\title{
Modeling Disorder in Pyrochlores and Other Anion-Deficient Fluorite Structural Derivative Oxides
}

\author{
V. Kocevski, G. Pilania and B. P. Uberuaga* \\ Materials Science and Technology Division, Los Alamos National Laboratory, Los Alamos, NM, United States
}

OPEN ACCESS

Edited by:

Gordon James Thorogood,

Australian Nuclear Science and Technology Organisation, Australia

Reviewed by: Andrzej Grzechnik, RWTH Aachen University, Germany Sabine Wurmehl, Leibniz Institute for Solid State and Materials Research Dresden (IFW

Dresden), Germany

${ }^{*}$ Correspondence:

B. P. Uberuaga blas@lanl.gov

Specialty section:

This article was submitted to Solid State Chemistry, a section of the journal Frontiers in Chemistry

Received: 20 May 2021 Accepted: 08 July 2021 Published: 31 August 2021

Citation:

Kocevski V, Pilania G and Uberuaga BP (2021) Modeling Disorder in Pyrochlores and Other Anion-Deficient Fluorite Structural Derivative Oxides.

Front. Chem. 9:712543. doi: 10.3389/fchem.2021.712543
Their very flexible chemistry gives oxide materials a richness in functionality and wide technological application. A specific group of oxides that have a structure related to fluorite but with less oxygen, termed anion-deficient fluorite structural derivatives and with pyrochlores being the most notable example, has been shown to exhibit a diversity of useful properties. For example, the possibility to undergo a transition from an ordered to disordered state allows these oxides to have high radiation tolerance. Atomistic-scale calculations in the form of molecular dynamics (MD) and density functional theory (DFT) have been extensively used to understand what drives this order/disorder transition. Here we give a brief overview of how atomistic-scale calculations are utilized in modeling disorder in pyrochlores and other anion-deficient fluorite structural derivatives. We discuss the modeling process from simple point defects to completely disordered structures, the dynamics during the disordering process, and the use of mathematical models to generate ordered solid-solution configurations. We also attempt to identify the challenges in modeling short range order and discuss future directions to more comprehensive models of the disordered structures.

Keywords: fluorite, disorder-compounds, atomistic material modelling, pyrochlore, short range order (SRO)

\section{INTRODUCTION}

Fluorite structural derivatives-oxides with a crystal structure related to fluorite-have attracted great interest both in fundamental research and in application. From the anion-deficient fluorite structural derivatives, pyrochlores, with a general formula $\mathrm{A}_{2} \mathrm{~B}_{2} \mathrm{O}_{7}$ ( $\mathrm{Fd} \overline{3} \mathrm{~m}$ space group), have attracted significant attention for various technological applications owing to their structural flexibility and special defect dynamics. They have been investigated as thermal barrier coatings (Lehmann et al., 2003; Cao et al., 2004; Schelling et al., 2004; Wu et al., 2004; Tryon et al., 2006; Winter and Clarke, 2007; Vaßen et al., 2010; Pan et al., 2012; Tanaka et al., 2017), solid oxide fuel cells (Heremans et al., 1995; Diazguillen et al., 2008; Kumar et al., 2008), solid oxide fuel cells (Wuensch, 2000; Pirzada, 2001; Yamamura, 2003; Shlyakhtina and Shcherbakova, 2012), quantum spin liquids (Anderson, 1973; Balents, 2010; Clark et al., 2014), high entropy oxides (Li et al., 2019; Zhao et al., 2019; Wright et al., 2021), and superconducting (Hanawa et al., 2001; Hanawa et al., 2002) and ferromagnetic/multiferroic (Greedan, 2006; Gardner et al., 2010; Wiebe and Hallas, 2015) materials. They have also attracted special interest as nuclear waste forms (Sickafus, 2000; Wang et al., 2000; Begg et al., 2001; Lian et al., 2003a; Lian et al., 2003b; Ewing et al., 2004; Helean et al., 2004; Lian et al., 2006; Lumpkin, 2006; Sickafus et al., 2007; Hartmann et al., 2011; Li et al., 2012; Sattonnay et al., 2013; Fischer et al., 2015; Raison and Haire, 2001; Lutique et al., 2003) and inert matrix fuel materials due to their high radiation tolerance. The high radiation tolerance of 


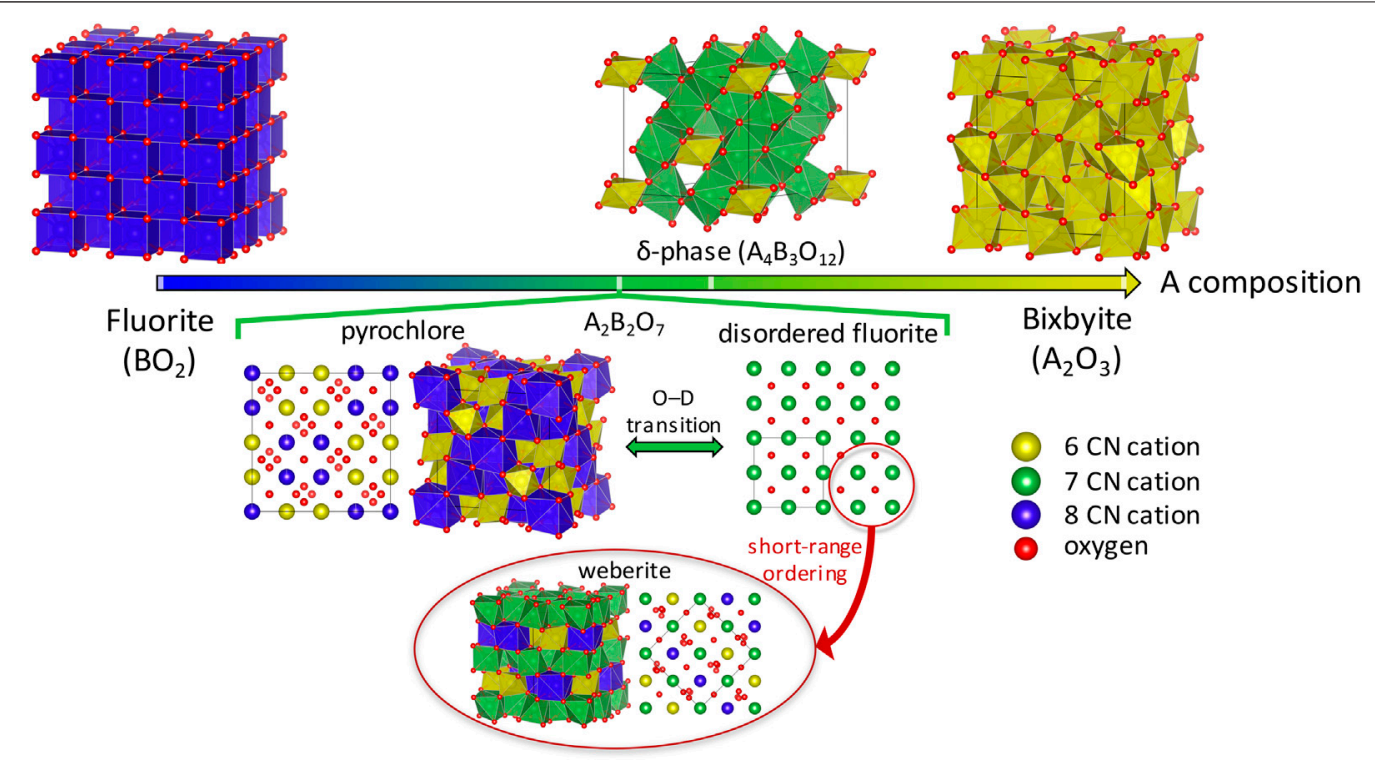

FIGURE 1 | Schematic representation of the anion-deficient fluorite structural derivative oxides, going from a fluorite $\left(\mathrm{BO}_{2}\right)$ to a bixbyite $\left(\mathrm{A}_{2} \mathrm{O}_{3}\right) \mathrm{crystal}$ structure. The cationic sites with coordination number $(\mathrm{CN})$ of 6,7 and 8 are shown as yellow, green, and blue spheres and polyhedra, respectively, while the oxygen atoms are shown as red spheres. The lower half highlights how, upon disordering, a fluorite-derivative structure such as pyrochlore can undergo an order-disorder transition to a structure resembling disordered fluorite on the long-range, but has short-range order more accurately described by a weberite-structure.

some pyrochlores is related to their ability to undergo an orderdisorder transition (Subramanian et al., 1983; Lang et al., 2010; Blanchard et al., 2012; Blanchard et al., 2013; FarmerMatt et al., 2014; Popov et al., 2016; Popov et al., 2018), i.e., a low thermodynamic barrier for transition from an ordered pyrochlore to a disordered fluorite structure. In contrast, pyrochlores that have high energy cost for the order-disorder transition would amorphize under irradiation (Sickafus, 2000). Understanding the disordering process and its impact on properties is critical for a number of other applications, including ionic conductors (Kreller and Uberuaga, 2021). We note that, in contrast, spinels $\left(\mathrm{AB}_{2} \mathrm{O}_{4}\right)$, which have a crystal structure related to rocksalt and have ordered cation vacancy sites, show opposite correlation between disordering energies and amorphization resistance compared to pyrochlores (Uberuaga et al., 2015), i.e., spinels that are more difficult to disorder exhibiting higher resistance to amorphization. Further, we use the term 'disorder' to mean chemical disorder in a crystalline matrix, while 'amorphization' refers to the loss of crystallinity.

The pyrochlore crystal structure can be described as an anion deficient $2 \times 2 \times 2$ superstructure of a fluorite $\left(\mathrm{BO}_{2}\right)$, having two ordered cation sites ( $\mathrm{A}$ in $16 d$ and $\mathrm{B}$ in $16 c$ Wykoff positions), two ordered oxygen sites ( $48 f$ and $8 b$ ), and an ordered oxygen vacancy site $(8 a)$ (see Figure 1). It has been commonly accepted that the order-disorder transition is driven by the formation of cation antisite pairs and oxygen Frenkel pairs. Another anion deficient fluorite derivative termed as $\delta$-phase (see Figure 1), with the general formula $\mathrm{A}_{4} \mathrm{~B}_{3} \mathrm{O}_{12}$, is also known to exhibit a high radiation tolerance that can be attributed to the transition from an ordered $\delta$-phase to a disordered fluorite (Sickafus et al., 2007) structure, also promoted by the formation of cation antisites and oxygen Frenkels (Sickafus et al., 2007; Stanek et al., 2009). Generally, such a transition occurs under high energy irradiation (Sickafus, 2000; Lian et al., 2003a; Lian et al., 2003b; Helean et al., 2004) (though disorder can also be induced by temperature and synthesis conditions), and thus modeling studies of the order-disorder transition have been focused on relating the formation of these defects with radiation tolerance of pyrochlores and $\delta$-phase. A further increase in the $\mathrm{O}$ vacancies gives the bixbyite structure with $\mathrm{A}_{2} \mathrm{O}_{3}$ composition, having $1 / 4 \mathrm{O}$ vacancies in the fluorite structure. However, unlike the pyrochlore and the $\delta$-phase, the disordered bixbyite does not have a fluorite structure, and thus we are not going to discuss it further in this review.

Studies of disordered pyrochlores suggest that the shortrange structure is more ordered than is described by the random disordered fluorite structure (Liu et al., 2004; Ushakov et al., 2007; Saradhi et al., 2012; Norberg et al., 2012; Zhang et al., 2013). Recently it was shown using neutron total scattering experiments with pair distribution function (PDF) analysis that disordered pyrochlore $\left(\mathrm{Ho}_{2} \mathrm{Zr}_{2} \mathrm{O}_{7}\right)$ has the atomic arrangement of the defect fluorite on a long-range scale, but the short-range ordering is better explained by a partially ordered orthorhombic phase that is well described by a weberite-type $\left(\mathrm{C} 222_{1}\right.$ space group) structural model (Shamblin et al., 2016). Weberite is also a superstructure of fluorite with a unit cell of $2 \times \sqrt{ } 2 \times \sqrt{ } 2$; it is more ordered than disordered fluorite but less ordered than pyrochlore. Unlike pyrochlore where A and B cations occupy 
the 8- and 6-fold coordinated sites, respectively, in weberite the $\mathrm{A}$ and $\mathrm{B}$ cations occupy 8 - and 6 -fold coordinated $4 b$ sites, respectively, while the 7 -fold coordinated $8 c$ site is equally occupied by both cations (see Figure 1). Note that 2-2-7 chemistries with weberite structure containing rare-earth cations have not been experimentally reported (Cai and Nino, 2009) (see Figure 2A), and, as far as we have found, there is only one experimental report of a 2-2-7 chemistry, $\mathrm{Ca}_{2} \mathrm{Sb}_{2} \mathrm{O}_{7}$, that undergoes a pyrochlore-to-weberite transformation at $973 \mathrm{~K}$ (Brisse et al., 1972).

In the past three decades, atomic scale calculations, by means of molecular dynamics (MD) simulations with interatomic potentials and density functional theory (DFT) calculations, have been extensively used to understand the disordering process in pyrochlores by calculating the intrinsic defects formation energies (Wilde, 1998; Chartier et al., 2002; Minervini et al., 2002; Minervini et al., 2004; Panero et al., 2004; Rushton et al., 2007; Sickafus et al., 2007; Chen et al., 2008; Chen and Tian, 2010; Gunn et al., 2012; Chen et al., 2014; Uberuaga et al., 2014; Li et al., 2015; Li and Kowalski, 2018; Yang et al., 2019), looking at dynamical processes (Chartier et al., 2002; Chartier et al., 2005; Devanathan and Weber, 2005; Todorov et al., 2006; Rushton et al., 2007; Chartier et al., 2009; Devanathan et al., 2010; Xiao et al., 2010; Wang et al., 2013; Uberuaga et al., 2014) (Xiao et al., 2015; Dong et al., 2017), and using models of disordered configurations for DFT calculations (Wolff-Goodrich et al., 2015; Jiang et al., 2009; Solomon et al., 2016; Finkeldei et al.,
2017; Pilania et al., 2019; Kowalski, 2020; Matsumoto et al., 2020). The simplest way to study the disorder in a material using atomistic scale calculations is to obtain the formation energies of intrinsic defects in ordered systems, which are generally accessible at a much lower computational cost than completely disordered systems. Although these dilute-limit defect energies only reflect the initial steps of disorder, they can give valuable information and qualitative agreement with experiments. In the case of pyrochlores, the basic premise would be that the formation energy of point defects, such as cation antisites, correlates with the energy to fully disorder the crystal (Uberuaga et al., 2014). A step between the study of intrinsic defects and complete disorder is analyzing dynamical processes in pyrochlores, such as threshold displacement energies, heavy ion track simulations, collision cascades, and defect accumulation. Such studies provide additional information on the energetic cost to disorder the system beyond the static intrinsic defect studies.

Performing similar simulations using ab initio MD (AIMD) is prohibitively expensive, thus a static model of the disordered fluorite is needed for DFT calculations. Such models of the disorder can be generated by arranging the A and B cations and the oxygen vacancies in a fluorite supercell, creating a special quasirandom structure (SQS) (Zunger et al., 1990) or a small set of ordered structures (Jiang and Uberuaga, 2016) such that their most relevant radial correlation functions mimic a perfectly random structure. These models provide the opportunity to compare the properties of both the ordered (pyrochlore) and
A

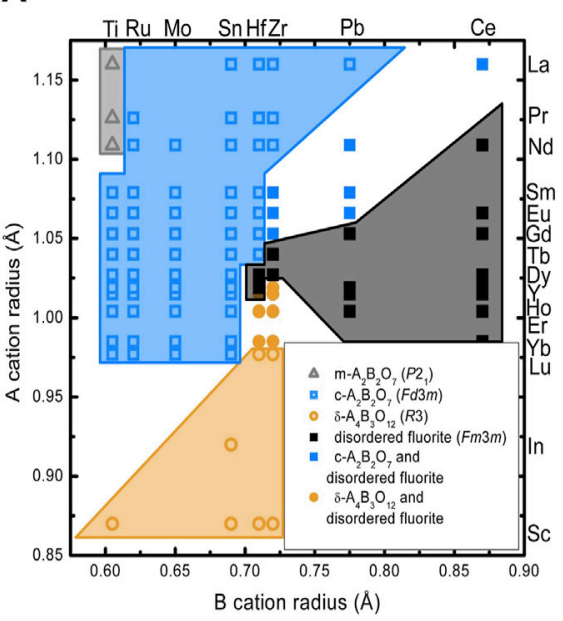

B
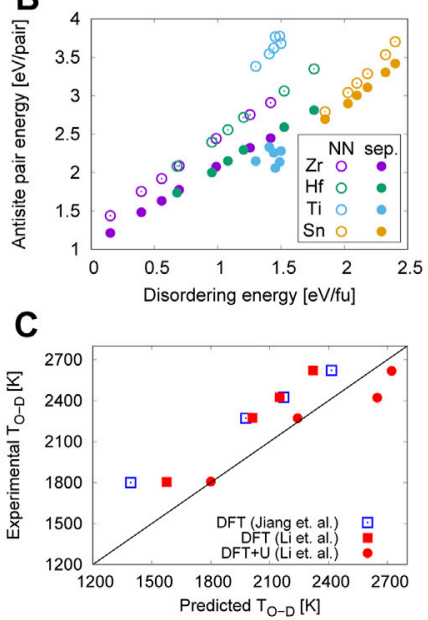

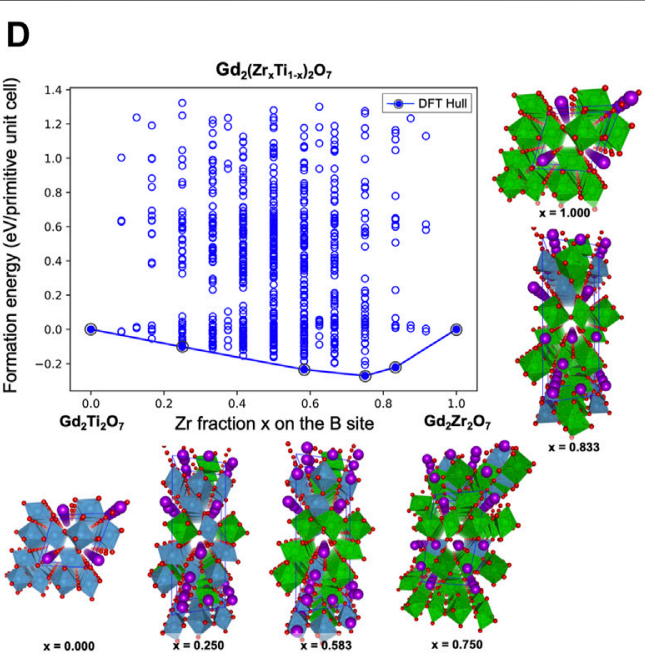

FIGURE 2 | (A) Structure map for $\mathrm{A}_{3}+\mathrm{B}_{4}+\mathrm{O}_{4}-\mathrm{x}$ compounds from experimentally reported structures. Hollow gray triangles denote the monoclinic $\mathrm{A}_{2} \mathrm{~B}_{2} \mathrm{O}_{7}$ structure, hollow blue squares denote $\mathrm{A}_{2} \mathrm{~B}_{2} \mathrm{O}_{7}$ pyrochlore, and hollow orange circles denote the rhombohedral $\Gamma$-phase $\mathrm{A}_{4} \mathrm{~B}_{3} \mathrm{O}_{12}$. Solid black squares denote disordered fluorite. Solid symbols of the same shape as stable ordered structures denote that both the ordered structure and disordered fluorite have been observed. Reproduced from (Stanek et al., 2009). (B) Formation energy of cation antisite pairs in four families of rare earth (RE) pyrochlores, $\mathrm{RE} \mathrm{B}_{2} \mathrm{O}_{7}(\mathrm{~B}=\mathrm{Zr}$, $\mathrm{Hf}$, Ti, $\mathrm{Sn}$ ), as a function of their disordering energies (calculated as described in (Jiang et al., 2009) and antisite separation distance. The formation energies when antisites are nearest neighbors (NN) and are separated (sep.) are shown with filled and open symbols, respectively. Adapted from (Uberuaga et al., 2014). (C) Comparison of the calculated order-disorder (O-D) transition temperature with experimental data (Stanek and Grimes, 2002) and (Rushton et al., 2004) for selected pyrochlores. The DFT results by (Jiang et al., 2009) and (Li et al., 2015) are shown in blue and red squares, respectively, and the DFT + U results by (Li et al., 2015) are shown in red circles. Reproduced from (Li et al., 2015). (D) Calculatedmixing energies per primitive unit cell for the 704 unique configurations enumerated within the $\mathrm{Gd}_{2}\left(\mathrm{Zr}_{\mathrm{x}} \mathrm{Ti}_{1}-\mathrm{x}\right)_{2} \mathrm{O}_{7}$ chemistries. The DFT predicted convex hull is represented as a solid line. The atomistic configurations for the identified ground-state ordered structures on the convex hull are illustrated using purple and red spheres for Gd and O, respectively, while Ti and Zr polyhedra are depicted in blue and green colors, respectively. Reproduced from (Pilania et al., 2019). 
disordered (fluorite) phases. Another approach, which can also be used to examine alternative cation arrangements and their temperature dependence via Monte Carlo, is cluster expansion (CE). Below we summarize how the above-mentioned methods are used in analyzing the order-disorder transition in anion deficient fluorite derivative phases, with a focus on pyrochlore as this system has been most extensively studied.

\section{DEFECT FORMATION}

The defect formation energies of pyrochlores were initially studied beginning more than 20 years ago using interatomic potentials (Wilde, 1998; Chartier et al., 2002; Minervini et al., 2002; Minervini et al., 2004; Rushton et al., 2007; Sickafus et al., 2007; Gunn et al., 2012), while recently more accurate DFT calculations have also been utilized (Panero et al., 2004; Chen et al., 2008; Zhang et al., 2009; Chen and Tian, 2010; Chen et al., 2014; Uberuaga et al., 2014; Li et al., 2015; Li and Kowalski, 2018; Yang et al., 2019). Despite the higher defect formation energies calculated using interatomic potentials compared to DFT, both types of studies show an apparent correlation between decreased cation antisite pair formation energies and the radiation tolerance of pyrochlores. Both also report a peak in the defect formation energies at $\mathrm{Gd}$ in the $\mathrm{A}_{2} \mathrm{Ti}_{2} \mathrm{O}_{7}$ series, which agrees with the experimentally observed highest critical amorphization temperature for $\mathrm{Gd}_{2} \mathrm{Ti}_{2} \mathrm{O}_{7}$ (Lian et al., 2003a). (Uberuaga et al. 2014) saw precisely these relationships in $\mathrm{Ti}$ and other pyrochlore chemistries (Figure 2B).

Once the oxygen Frenkel is coupled with a cation antisite pair, the formation energy of such clusters becomes lower than the isolated defects (with a few exceptions (Li et al., 2015; Li and Kowalski, 2018)). This enhanced stability of the clusters indicates that cation antisites cause local oxygen disorder, and hence, drive the formation of disordered fluorite structure. (Stanek and Grimes, 2002) and (Rushton et al., 2004) correlated the formation energies of these clusters with the experimental pyrochlore-to-disordered-fluorite transition temperatures for $\mathrm{A}_{2} \mathrm{Hf}_{2} \mathrm{O}_{7}$ and $\mathrm{A}_{2} \mathrm{Zr}_{2} \mathrm{O}_{7}$, respectively, showing a clear linear relation. Studies with potentials also report a threshold cluster formation energy below which disordered fluorite is preferred, demonstrating why some chemistries do not form the pyrochlore structure. (Yang et al., 2019) evaluated the defect formation energies in off-stoichiometric $\mathrm{A}_{2} \mathrm{~B}_{2} \mathrm{O}_{7}(\mathrm{~A}=\mathrm{La}, \mathrm{Nd}, \mathrm{Gd} ; \mathrm{B}=$ $\mathrm{Zr}, \mathrm{Hf}, \mathrm{Sn}$ ), demonstrating how the synthesis methods, i.e., excess of $\mathrm{A}_{2} \mathrm{O}_{3}$ or $\mathrm{BO}_{2}$, can influence the radiation tolerance of pyrochlores.

The most important observations from these studies are that the energetics of cation antisites correlate with the amorphization resistance of the material and that cation and oxygen disordered are coupled. The correlation between disordering and amorphization has been explained by (Sickafus, 2000) as related to an inherent ability of the structure to create lowenergy defects that do not drastically increase the stored energy in the material. On the other hand, that cation and anion disorder are linked is a consequence of the differences in preferred coordination in the $\mathrm{A}$ and $\mathrm{B}$ cations -8 and 6 , respectively. As the cations are disordered, they will naturally drive rearrangement of the oxygen to best retain their preferred coordination, and these modeling results directly demonstrate this fact. However, this behavior is not universal, as we will see in our discussion of the $\delta$-phase structure below.

\section{DYNAMICAL PROCESSES}

Threshold displacement energies (TDEs) can characterize the resistance of a given sublattice to short-range displacements in a specific crystallographic direction, by looking at the response of the crystal to a primary knock-on atom (PKA). The TDE of pyrochlores have been studied using classical MD Chartier et al., 2002; Devanathan and Weber, 2005; Dong et al., 2017) and AIMD (Xiao et al., 2010; Wang et al., 2013; Xiao et al., 2015). While both MD and AIMD give the same trend in terms of which species are easiest to displace, the calculated TDEs do not correlate with the experimental radiation tolerance of the studied $\mathrm{A}_{2} \mathrm{Ti}_{2} \mathrm{O}_{7}$ pyrochlores.

More detailed understanding of the main mechanisms that promote the formation of disordered fluorite, and subsequently an amorphous phase, can be gained by investigating dynamical processes during collision cascades. Collision cascades in $\mathrm{La}_{2} \mathrm{Zr}_{2} \mathrm{O}_{7}$ (Chartier et al., 2003) and $\mathrm{Gd}_{2} \mathrm{~B}_{2} \mathrm{O}_{7}(\mathrm{~B}=\mathrm{Ti}, \mathrm{Zr}, \mathrm{Pb})$ (Todorov et al., 2006; Rushton et al., 2007) display very similar behavior, with significantly higher number of $\mathrm{O}$ defects compared to cation defects at the end of the simulation. Despite this, the oxygen-oxygen radial distribution function of the studied pyrochlores shows no hints of amorphization. A closer look into the equilibrated structures shows that most of the displaced $\mathrm{O}$ atoms in the studied pyrochlores recovered to an equilibrium site (48f, $8 \mathrm{~b}$ or $8 \mathrm{a}$ ), except for in $\mathrm{Gd}_{2} \mathrm{Ti}_{2} \mathrm{O}_{7}$ where the formed $\mathrm{O}$ defects are in interstitial sites.

Another way to study disordering processes is by simulating swift heavy ion irradiation tracks using thermal spikes. By such simulations in $\mathrm{Gd}_{2} \mathrm{Zr}_{\mathrm{x}} \mathrm{Ti}_{2-\mathrm{x}} \mathrm{O}_{7}$, (Devanathan et al., 2013) showed that an amorphous area of $\sim 2 \mathrm{~nm}$ forms in $\mathrm{Gd}_{2} \mathrm{Ti}_{2} \mathrm{O}_{7}$, which shrinks with increasing $\mathrm{Zr}$ content, and completely disappears in $\mathrm{Gd}_{2} \mathrm{Zr}_{2} \mathrm{O}_{7}$. The findings agree with experiments that show that $\mathrm{Gd}_{2} \mathrm{Ti}_{2} \mathrm{O}_{7}$ becomes amorphous under swift heavy ion irradiation while $\mathrm{Gd}_{2} \mathrm{Zr}_{2} \mathrm{O}_{7}$ forms disordered fluorite. A closer look into the disordering process in $\mathrm{Gd}_{2} \mathrm{Ti}_{2} \mathrm{O}_{7}$ showed a formation of $\mathrm{Gd}$ vacancies, Ti interstitials, and Gd-on-Ti antisites that facilitate amorphization. On the other hand, only $\mathrm{Gd}$ and $\mathrm{Zr}$ antisite pairs are observed in $\mathrm{Gd}_{2} \mathrm{Zr}_{2} \mathrm{O}_{7}$, which dissipate the excess energy.

As we discussed previously, the tendency of a pyrochlore to disorder, i.e., to form a disordered fluorite structure, is correlated with the formation energy of cation antisites and oxygen Frenkels. A more complete picture of disordering in the pyrochlore structure can be gained by introducing defects in various concentrations, and using $\mathrm{MD}$ to simulate the disordering process over time. Using classical MD simulations of $\mathrm{La}_{2} \mathrm{Zr}_{2} \mathrm{O}_{7}$ pyrochlore, (Chartier et al., 2005) showed that cation antisites induce disorder on the oxygen sublattice, indicating that the transition to a disordered fluorite is driven by cation disorder. 
Later (Chartier et al., 2009) extended their study to $\mathrm{Gd}_{2} \mathrm{Zr}_{\mathrm{x}} \mathrm{Ti}_{2-}$ ${ }_{\mathrm{x}} \mathrm{O}_{7}$ solid solutions, showing a decrease in radiation tolerance with increasing $\mathrm{Ti}$ content, while (Devanathan et al., 2010) compared the two end-member compositions. Both studies show that the amorphization of pyrochlores is a two-step process: initially cation antisites and oxygen Frenkels are formed, with subsequent damage increasing the concentration of cation Frenkels, especially $\mathrm{Ti}-\mathrm{Ti}$ dumbbells which resist recombination, leading to amorphization. These studies reveal that simply introducing cation disorder leads to disordering of the entire structure-the anions disorder "spontaneously" in the presence of cation disorder.

Together, these dynamical simulations both reinforce the conclusions obtained from the static calculations of defects but also reveal new details of the dynamical processes underlying the formation of disorder. During irradiation, oxygen is always easier to displace, but unless cations are also displaced, that disorder oxygen structure will not persist. Cation antisites are the driver of disorder on both sublattices. However, at some defect concentration, the lattice becomes unstable and cation Frenkels start to form. The lack of dynamical recovery leads to an exceedingly high stored energy for some chemistries, which causes amorphization. Thus, the susceptibility to amorphization is a combination of both the energetic cost of the defects that are unavoidably introduced during irradiation and their inability to heal or recombine. What is still missing in the literature is a model that can actually predict the rate of amorphization for a given material as a function of temperature and dose. We suspect this is due to the shear difficulty in developing such a model for even one compound, given all of the details that must be addressed. However, such a model for even one compound would provide important insight into the most critical factors describing the kinetics of amorphization and recovery.

\section{STRUCTURAL DISORDER}

As mentioned, one can use SQS to model the disordered fluorite structure with DFT, and evaluate the energy for disordering as the energy difference between the ordered pyrochlore and the disordered SQS. (Jiang et al., 2009) used this approach to calculate the disordering energy for a set of rare-earth pyrochlores, $\mathrm{A}_{2} \mathrm{~B}_{2} \mathrm{O}_{7}(\mathrm{~A}=\mathrm{Pr}, \mathrm{Nd}, \mathrm{Sm}, \mathrm{Gd}, \mathrm{Tb}, \mathrm{Dy}, \mathrm{Er} ; \mathrm{B}=\mathrm{Ti}$, $\mathrm{Zr}, \mathrm{Hf}, \mathrm{Sn}$ ), while (Li et al., 2015) focused on a small subset of pyrochlores $\left(\mathrm{Gd}_{2} \mathrm{Zr}_{2} \mathrm{O}_{7}, \mathrm{Gd}_{2} \mathrm{Hf}_{2} \mathrm{O}_{7}, \mathrm{Sm}_{2} \mathrm{Zr}_{2} \mathrm{O}_{7}, \mathrm{~Tb}_{2} \mathrm{Zr}_{2} \mathrm{O}_{7}\right)$. Both related the disordering energy with amorphization tendencies and estimated the order-disorder temperature, $T_{\mathrm{OD}}$, showing good agreement with experiments (Figure 2c) and highlighting the relevance of the disordered state in understanding the properties of these materials. Using the calculated $T_{\mathrm{OD}}$, (Jiang et al., 2009) were also able to explain the difficulties in synthesizing of some pyrochlores. More importantly, as highlighted in Figure 2B, these types of calculations (Uberuaga et al., 2014) reveal a direct correlation between the energetics of cation antisite pairs and full disorder in the system.
Recently, Shamlin et al. showed experimentally that the weberite-like structure, which has a random cationic distribution on the $8 c$ site (7-fold coordinated site), best represents the short-range order in the disordered structure (Shamblin et al., 2016). This has inspired DFT calculations of weberite-type disordered structures (Solomon et al., 2016; Finkeldei et al., 2017; Kowalski, 2020; Matsumoto et al., 2020), which show that disordered fluorite has higher energy than disordered weberite. It is argued that this indicates a possibility of forming weberite-type short-range ordering. However, both (Kowalski, 2020) and (Matsumoto et al., 2020) also report that some $\mathrm{A}_{2} \mathrm{~B}_{2} \mathrm{O}_{7}$ chemistries have weberite-type as a lower energy configuration, in disagreement with experiments that report either pyrochlore or $\delta$-phase (Figure 2A). This is a curious result as no 2-2-7 chemistries containing +3 and +4 cations have been experimentally reported to have the weberite structure (Cai and Nino, 2009). On the other hand, calorimetry experiments indicate that the short-range order described by weberite is higher in energy than pyrochlore (Solomon et al., 2016; Finkeldei et al., 2017). The discrepancy between experiments and modeling can be explained for some chemistries, namely $\mathrm{A}_{2} \mathrm{Zr}_{2} \mathrm{O}_{7}$ and $\mathrm{A}_{2} \mathrm{Hf}_{2} \mathrm{O}_{7}(\mathrm{~A}=\mathrm{Ho}, \mathrm{Er}, \mathrm{Yb}$, $\mathrm{Lu}$ ), which form $\delta$-phase (see Figure $2 \mathrm{~A}$ ), suggesting $\delta$-phase might be preferred and thus should be examined. (Matsumoto et al., 2020) also used the vibrational entropy of the $\mathrm{Yb}_{2} \mathrm{Ti}_{2} \mathrm{O}_{7}$ pyrochlore and weberite to find the weberite-to-pyrochlore ordering transition temperature, showing that the pyrochlore ordering is preferred at temperatures above $500 \mathrm{~K}$. Nevertheless, the predicted ordering transition temperature is not low enough to explain why the weberite-type structure has not been experimentally observed.

Finally, there is a possibility of even greater ordering when multiple cations are introduced into one of the sublattices. Calculations of such structures can give further insight into the drivers of ordering and the relationship between cation and anion structure. (Pilania et al., 2020) have investigated precisely this possibility in $\mathrm{Gd}_{2}\left(\mathrm{Ti}_{1-\mathrm{x}} \mathrm{Zr}_{\mathrm{x}}\right)_{2} \mathrm{O}_{7}$ using cluster expansion coupled with DFT calculations. As highlighted in Figure 2D, their calculations indicated that $\mathrm{Gd}_{2}\left(\mathrm{Ti}_{0.25} \mathrm{Zr}_{0.75}\right)_{2} \mathrm{O}_{7}$, termed a double pyrochlore, has the lowest formation energy on the convex hull. The enhanced stability of this composition was attributed to a special configuration that allows for 7 -fold coordinated $\mathrm{Zr}$ sites while maintaining the preferred 6-fold coordination of Ti-atoms. This kind of cation-induced change in the local oxygen coordination is what is behind the formation of weberite-like short-range order.

In our view, one of the most important results from these calculations is that the energetics of the individual cation antisites correlate very strongly with full disorder. This directly links the original calculations of isolated defects and the fully disordered structure. However, more recent experiments and calculations of disordered structures also reveal what we might call a conundrum. It is now abundantly clear that short-range order exists in the disordered and even amorphous materials. However, the calculations indicate that structures built on these short-range ordered motifs are actually more stable than pyrochlore. We will discuss this in greater depth below. Finally, the unexpected 
stability of $\mathrm{Gd}_{2}\left(\mathrm{Ti}_{0.25} \mathrm{Zr}_{0.75}\right)_{2} \mathrm{O}_{7}$, in which $\mathrm{Zr}$ is able to attain its preferred 7 -fold coordination, suggests that, in the pyrochlore structure, $\mathrm{Zr}$ is frustrated. This may explain why $\mathrm{Zr}$-based pyrochlores tend to be fast ion conductors, as the oxygen struggles to maintain low-energy coordination in any one configuration.

\section{OTHER PHASES}

The $\delta$-phase was initially presented as having a higher radiation tolerance as compared to pyrochlores by (Sickafus et al., 2007), which they correlate with the lower formation energy of defect clusters. Following these findings, (Stanek et al., 2009) performed a computational study of the cation ordering in $\mathrm{A}_{4} \mathrm{~B}_{3} \mathrm{O}_{12}$ and calculated the disordering energy with respect to the disordered fluorite. (Interestingly, these compounds have not been experimentally observed to have cation order.) They then evaluated the $T_{\mathrm{OD}}$ using the same approach as (Jiang et al., 2009). The $T_{\mathrm{OD}}$ were found to be generally low, even lower compared to most of the pyrochlores from study, indicating that the $\delta$-phase should disorder much more easily, and thus have high radiation tolerance, as initially indicated by static MD calculations (Sickafus et al., 2007).

Until now our discussion has focused on the specific compositions $\mathrm{A}_{2} \mathrm{~B}_{2} \mathrm{O}_{7}$ and $\mathrm{A}_{4} \mathrm{~B}_{3} \mathrm{O}_{12}$. However, it is possible to sample the whole phase space between $\mathrm{BO}_{2}$ and $\mathrm{A}_{2} \mathrm{O}_{3}$ for any stable ordered fluorite structural derivative compounds. This is what (Bogicevic et al., 2001; Bogicevic and Wolverton, 2003) and (Predith et al., 2008) did using cluster expansion to find the lowest energy ordering in the $\mathrm{ZrO}_{2}-\mathrm{A}_{2} \mathrm{O}_{3}(\mathrm{~A}=\mathrm{Y}, \mathrm{Sc})$ and $\mathrm{ZrO}_{2}-\mathrm{Y}_{2} \mathrm{O}_{3}$ phase spaces, respectively. In addition to the experimentally observed $\delta$-phases $\left(\mathrm{Y}_{4} \mathrm{Zr}_{3} \mathrm{O}_{12}\right.$ and $\left.\mathrm{Sc}_{4} \mathrm{Zr}_{3} \mathrm{O}_{12}\right)$, both report $\mathrm{Y}_{2} \mathrm{Zr}_{5} \mathrm{O}_{10}$ and $\mathrm{Sc}_{2} \mathrm{Zr}_{5} \mathrm{O}_{10}$ to be stable with respect to cubic $\mathrm{ZrO}_{2}$, while (Predith et al., 2008) also report an additional $\mathrm{Y}_{2} \mathrm{Zr}_{4} \mathrm{O}_{11}$ stable phase. Furthermore, Predith et al. show that only $\mathrm{Y}_{2} \mathrm{Zr}_{4} \mathrm{O}_{11}$ and $\mathrm{Y}_{4} \mathrm{Zr}_{3} \mathrm{O}_{12}$ phases are stable with respect to the monoclinic, lowest energy $\mathrm{ZrO}_{2}$. None of these studies found the pyrochlore configuration to be stable, in agreement with experiments where only the stable $\delta$-phase is observed for these compositions. In the reported stable structures, the oxygen vacancies align along the $<111>$ direction and are always third nearest neighbors to each other, showing that cluster expansion can provide information on the short-range ordering in solid solutions. Such studies have been performed for other crystal structures, such as spinels (Jiang et al., 2012; Pilania et al., 2020), but have not been applied to fluorite derivatives as extensively because of the need to account for the coupling of disorder on the cation and anion sublattices.

These calculations both complement and contrast with the behavior we have described for pyrochlore. First, that the $\delta$-phase structure is easy to disorder suggests it has high radiation tolerance, as has been observed (Sickafus et al., 2007). However, this structure also exhibits anion ordering despite the disordered cations, indicating that cation disorder does not always force anion disorder. Oxygen vacancy-vacancy repulsion, presumably, overcomes any coupling with the cation disorder.
Further, as demonstrated by there can be a variety of other stable structures for some of these chemistries, suggesting that there is not one dominant phase and that short-range order in disordered materials may be related to these other structures as well. This has not been considered in prior research, to the best of our knowledge.

\section{DISCUSSION AND OUTLOOK}

The computational studies we have examined have provided invaluable insight into the nature of disorder in aniondeficient fluorite derivatives. It is only through atomistic modeling that the relationship between disordering and radiation tolerance has been established. However, there are a number of questions that arise from past work that can be uniquely addressed by future modeling efforts.

Classical MD simulations provide a good understanding of the processes that drive the disordering of pyrochlores to a disordered fluorite structure. However, the accuracy of MD simulations is dependent on the quality of the interatomic potential and current potentials do not capture all of the nuances of the true quantum system, such as the formation of 7 -fold coordinated $\mathrm{Zr}$ sites predicted using DFT in $\mathrm{Gd}_{2}\left(\mathrm{Ti}_{0.25} \mathrm{Zr}_{0.75}\right)_{2} \mathrm{O}_{7}$ (Pilania et al., 2019). Thus, new potentials could improve the understanding of the disordering processes in pyrochlores. Alternatively, AIMD using DFT forces can be performed directly to understand the disordering processes by introducing different defects in various concentrations in the simulation cells, similarly to some of the classical MD studies discussed above. Such simulations can validate classical results and provide new insight into how chemical bonding drives unique behavior. While AIMD simulations are currently computationally highly expensive, current improvements in code efficiency and computational architectures can make such simulations possible.

Using DFT calculations, SQS models of disordered fluorite provide a reasonable estimate of the $T_{\mathrm{OD}}$ of pyrochlores (Jiang et al., 2009; Li et al., 2015), with $T_{\text {OD }}$ calculated with DFT $+U$ being in very good agreement with experiments ( $\mathrm{Li}$ et al., 2015). A more accurate estimate of $T_{\mathrm{OD}}$ can be obtained by accounting for vibrational entropy, as has been demonstrated in spinels (Jiang et al., 2012). Introducing the vibrational entropy to the defect formation energies can also provide more rigorous defect formation free energies, as well as a possibility to evaluate the defect concentrations at finite temperatures. A critical unknown is how equilibrium defect concentrations depend on the state of disorder-all defect calculations that have been done are for the fully ordered state and may not be representative of the disordered material.

We have discussed how cluster expansion is a powerful tool for studying the energetics of disorder, such as finding order in solidsolutions of $\mathrm{Gd}_{2}\left(\mathrm{Ti}_{1-\mathrm{x}} \mathrm{Zr}_{\mathrm{x}}\right)_{2} \mathrm{O}_{7}$ (Pilania et al., 2019) and the mixing between $\mathrm{BO}_{2}$ and $\mathrm{A}_{2} \mathrm{O}_{3}$ (Predith et al., 2008). Therefore, cluster expansion can be employed to study the change from pyrochlore (ordered) to fluorite-type (disordered) structure in the studied $\mathrm{A}_{2}\left(\mathrm{~B}_{1-\mathrm{x}} \mathrm{B}_{\mathrm{x}}^{\prime}\right)_{2} \mathrm{O}_{7}$ solid solutions, accounting for mixing on the cationic sublattice between $\mathrm{A}, \mathrm{B}$ and $\mathrm{B}^{\prime}$ cations in addition to 
introducing $\mathrm{O}$ in the vacant $8 a$ sites. While there might be challenges in developing cluster expansion models that account for the coupled order between the cation and anion sublattices, this is an integral step that must be undertaken to fully understand the nature of the short-range order in disordered pyrochlores.

Even if the disordered state is properly understood and described, this is only the beginning. To predict and ultimately design materials that leverage the disordered state, we must also know the impact on properties. As we have already noted, disordered materials have unique properties distinct from their ordered counterparts. This fact has mostly been revealed by experiments with relatively little work by modeling. There is a need, once reasonable models of the disordered state have been established, to understand the structure-property relationship of those systems. Structural properties such as short-range order and percolation networks can have dramatic effects on transport and these relationships have received scant modeling attention (Kreller and Uberuaga, 2021).

Finally, the biggest question that arises from this review is the nature of the ordering in the presumably disordered fluorite structure of these materials. Experiments indicate that short range order is present. This should be expected, as no natural material is truly random-indeed, cluster expansion studies of spinel show that short range order persists to extremely high (and unphysical) temperatures (Pilania et al., 2020). However, the random structure presents a useful conceptual limit that has been demonstrated to correlate with experimental observables such as the order-disorder transition temperature and the critical

\section{REFERENCES}

Anderson, P. W. (1973). Resonating Valence Bonds: A New Kind of Insulator? Mater. Res. Bull. 8 (2), 153-160. doi:10.1016/0025-5408(73)90167-0

Balents, L. (2010). Spin Liquids in Frustrated Magnets. Nature 464 (7286), 199-208. doi:10.1038/nature08917

Begg, B. D., Hess, N. J., McCready, D. E., Thevuthasan, S., and Weber, W. J. (2001). Heavy-Ion Irradiation Effects in $\mathrm{Gd}_{2}\left(\mathrm{Ti}_{2-\mathrm{x}} \mathrm{Zr}_{\mathrm{x}}\right) \mathrm{O}_{7}$ Pyrochlores. J. Nucl. Mater. 289 (1-2), 188-193. doi:10.1016/s0022-3115(00)00696-6

Blanchard, P. E. R., Clements, R., Brendan, J. K., ChrisLing, D., Emily, R., Max, A., et al. (2012). Does Local Disorder Occur in the Pyrochlore Zirconates? Inorg. Chem. 51 (24), 13237-13244. doi:10.1021/ic301677b

Blanchard, P. E. R., Liu, S., Brendan, J. K., Chris, D. L., Max, A., JadeAitken, B., et al. (2013). Investigating the Local Structure of Lanthanoid Hafnates $\operatorname{Ln}_{2} \mathrm{Hf}_{2} \mathrm{O}_{7}$ via Diffraction and Spectroscopy. The J. Phys. Chem. C 117 (5), 2266-2273. doi:10.1021/jp311329q

Bogicevic, A., Wolverton, C., Crosbie, G. M., and Stechel, E. B. (2001). Defect Ordering in Aliovalently Doped Cubic Zirconia from First Principles. Phys. Rev. B 64 (1), 014106. doi:10.1103/physrevb.64.014106

Bogicevic, A., and Wolverton, C. (2003). Nature and Strength of Defect Interactions in Cubic Stabilized Zirconia. Phys. Rev. B 67 (2), 024106. doi:10.1103/physrevb.67.024106

Brisse, F., Stewart, D. J., Seidl, V., and Knop, O. (1972). Pyrochlores. VIII. Studies of Some 25 Pyrochlores and Related Compounds and Minerals. Can. J. Chem. 50 (22), 3648-3666. doi:10.1139/v72-580

Cai, L., and Nino, J. C. (2009). Complex Ceramic Structures. I. Weberites. Acta Crystallogr. Section B Struct. Sci. 65 (3), 269-290. doi:10.1107/s0108768109011355

Cao, X. Q., Vassen, R., and Stoever, D. (2004). Ceramic Materials for thermal Barrier Coatings. J. Eur. Ceram. Soc. 24 (1), 1-10. doi:10.1016/s0955-2219(03) 00129-8 temperature for amorphization. Thus, the random structure does capture some of the physical behavior of the real materials. The key question then is when is it critical to account for the shortrange order to accurately understand and predict the properties of these materials. For example, it seems clear that the nature of the short-range order is essential for understanding mass transport in these materials (Kreller and Uberuaga, 2021). However, it isn't necessary to understand chemical trends in thermodynamic behavior. Future work must elucidate not only the nature of the short-range order, but when it must be accounted for.

\section{AUTHOR CONTRIBUTIONS}

VK, GP, and BU conceived of and planned the manuscript. VK researched the literature and wrote the main body of the manuscript. All of the authors edited and contributed to the manuscript. All authors contributed to the figures.

\section{FUNDING}

This work was supported by the U.S. Department of Energy, Office of Science, Basic Energy Sciences, Materials Sciences and Engineering Division. Los Alamos National Laboratory is operated by Triad National Security, LLC, for the National Nuclear Security Administration of U.S. Department of Energy (Contract No. 89233218CNA000001).

Chartier, A., Constantin, M., Jean-Paul, C., René Corrales, L., and Weber, W. J. (2003). Atomistic Modeling of Displacement Cascades in $\mathrm{La}_{2} \mathrm{Zr}_{2} \mathrm{O}_{7}$ Pyrochlore. Phys. Rev. B 67 (17), 174102. doi:10.1103/physrevb.67.174102

Chartier, A., Constantin, M., Weber, W. J., and René Corrales, L. (2002). Theoretical Study of Disorder in Ti-Substituted $\mathrm{La}_{2} \mathrm{Zr}_{2} \mathrm{O}_{7}$ Phys. Rev. B 65 (13), 134116. doi:10.1103/physrevb.65.134116

Chartier, A., Meis, C., Crocombette, J.-P., Weber, W. J., and Corrales, L. R. (2005). Molecular Dynamic Simulation of Disorder Induced Amorphization in Pyrochlore. Phys. Rev. Lett. 94 (2), 025505. doi:10.1103/physrevlett.94.025505

Chartier, A., Catillon, G., and Crocombette, J. P. (2009). Key Role of the Cation Interstitial Structure in the Radiation Resistance of Pyrochlores. Phys. Rev. Lett. 102 (15), 155503. doi:10.1103/physrevlett.102.155503

Chen, L., Su, X., and Li, Y. (2014). First-Principles Study on Cation-Antisite Defects of Stannate and Titanate Pyrochlores. OALib 01 (03), 1-8. doi:10.4236/ oalib.1100516

Chen, Z. J., Xiao, H. Y., Zu, X. T., and Gao, F. (2008). First-Principles Calculation of Defect Formation Energies and Electronic Properties in Stannate Pyrochlores. J. Appl. Phys. 104 (9), 093702. doi:10.1063/1.3000558

Chen, Z. J., and Tian, D. B. (2010). First-Principles Study of Disordering Tendencies in $\mathrm{Gd}_{2} \mathrm{~B}_{2} \mathrm{O}_{7}(\mathrm{~B}=\mathrm{Ti}, \mathrm{Sn}, \mathrm{Zr})$ Compounds. Chin. Phys. B 19 (12), 127101. doi:10.1088/1674-1056/19/12/127101

Clark, L., Nilsen, G. J., Kermarrec, E., Ehlers, G., Knight, K. S., Harrison, A., et al. (2014). From Spin Glass to Quantum Spin Liquid Ground States in Molybdate Pyrochlores. Phys. Rev. Lett. 113 (11), 117201. doi:10.1103/ physrevlett.113.117201

Devanathan, R., Weber, W. J., and Gale, J. D. (2010). Radiation Tolerance of Ceramicsinsights from Atomistic Simulation of Damage Accumulation in Pyrochlores. Energ. Environ. Sci. 3 (10), 1551. doi:10.1039/c0ee00066c

Devanathan, R., and Weber, W. J. (2005). Insights into the Radiation Response of Pyrochlores from Calculations of Threshold Displacement Events. J. Appl. Phys. 98 (8), 086110. doi:10.1063/1.2120889 
Devanathan, R., Gao, F., and Sundgren, C. J. (2013). Role of Cation Choice in the Radiation Tolerance of Pyrochlores. RSC Adv. 3 (9), 2901. doi:10.1039/ c2ra22745b

Diazguillen, J., Diazguillen, M., Padmasree, K., Fuentes, A., Santamaria, J., and Leon, C. (2008). High Ionic Conductivity in the Pyrochlore-type $\mathrm{Gd}_{2-\mathrm{y}} \mathrm{La}_{\mathrm{y}} \mathrm{Zr}_{2} \mathrm{O}_{7}$ Solid Solution $(0 \leq \mathrm{y} \leq 1)$. Solid State Ionics 179 (38), 2160-2164. doi:10.1016/j.ssi.2008.07.015

Dong, L., Setyawan, W., Li, Y., Devanathan, R., and Gao, F. (2017). Molecular Dynamics Simulation of Low-Energy Recoil Events in Titanate Pyrochlores. RSC Adv. 7 (56), 35403-35410. doi:10.1039/ c7ra04699e

Ewing, R. C., Weber, W. J., and Lian, J. (2004). Nuclear Waste DisposalPyrochlore $\left(\mathrm{A}_{2} \mathrm{~B}_{2} \mathrm{O}_{7}\right)$ : Nuclear Waste Form for the Immobilization of Plutonium and "Minor" Actinides. J. Appl. Phys. 95 (11), 5949-5971. doi:10.1063/1.1707213

Farmer, J. M., Boatner, L. A., Chakoumakos, B. C., Du, M.-H., Lance, M. J., Rawn, C. J., et al. (2014). Structural and Crystal Chemical Properties of Rare-Earth Titanate Pyrochlores. J. Alloys Compounds 605 (August), 63-70. doi:10.1016/ j.jallcom.2014.03.153

Finkeldei, S., Kegler, P., Kowalski, P. M., Schreinemachers, C., Brandt, F., Bukaemskiy, A. A., et al. (2017). Composition Dependent Order-Disorder Transition in NdxZr1-xO2-0.5x Pyrochlores: A Combined Structural, Calorimetric and Ab Initio Modeling Study. Acta Materialia 125 (February), 166-176. doi:10.1016/j.actamat.2016.11.059

Fischer, C., Finkeldei, S., Brandt, F., Bosbach, D., and Luttge, A. (2015). Direct Measurement of Surface Dissolution Rates in Potential Nuclear Waste Forms: The Example of Pyrochlore. ACS Appl. Mater. Inter. 7 (32), 17857-17865. doi:10.1021/acsami.5b04281

Gardner, J. S., GingrasGingras, M. J. P., and Greedan, J. E. (2010). Magnetic Pyrochlore Oxides. Rev. Mod. Phys. 82 (1), 53-107. doi:10.1103/revmodphys.82.53

Greedan, J. E. (2006). Frustrated Rare Earth Magnetism: Spin Glasses, Spin Liquids and Spin Ices in Pyrochlore Oxides. J. Alloys Compounds 408-412 (February), 444-455. doi:10.1016/j.jallcom.2004.12.084

Gunn, D. S. D., Allan, N. L., Foxhall, H., Harding, J. H., Purton, J. A., Smith, W., et al. (2012). Novel Potentials for Modelling Defect Formation and Oxygen Vacancy Migration in $\mathrm{Gd}_{2} \mathrm{Ti}_{2} \mathrm{O}_{7}$ and $\mathrm{Gd}_{2} \mathrm{Zr}_{2} \mathrm{O}_{7}$ Pyrochlores. J. Mater. Chem. 22 (11), 4675. doi:10.1039/c2jm15264a

Hanawa, M., Yamaura, J., Muraoka, Y., Sakai, F., and Hiroi, Z. (2002). Structural Phase Transition in the Superconducting Pyrochlore Oxide $\mathrm{Cd}_{2} \mathrm{Re}_{2} \mathrm{O}_{7}$. J. Phys. Chem. Sol. 63 (6-8), 1027-1030. doi:10.1016/s00223697(02)00090-2

Hanawa, M., Muraoka, Y., Tayama, T., Sakakibara, T., Yamaura, J., and Hiroi, Z. (2001). Superconductivity at $1 \mathrm{~K} \mathrm{inCd}_{2} \mathrm{Re}_{2} \mathrm{O}_{7}$. Phys. Rev. Lett. 87 (18), 187001. doi:10.1103/physrevlett.87.187001

Hartmann, T., Alaniz, A., Poineau, F., Weck, P. F., Valdez, J. A., Tang, M., et al. (2011). Structure Studies on Lanthanide Technetium Pyrochlores as Prospective Host Phases to Immobilize 99technetium and Fission Lanthanides from Effluents of Reprocessed Used Nuclear Fuels. J. Nucl. Mater. 411 (1-3), 60-71. doi:10.1016/j.jnucmat.2011.01.033

Helean, K. B., Ushakov, S. V., Brown, C. E., Navrotsky, A., Lian, J., Ewing, R. C., et al. (2004). Formation Enthalpies of Rare Earth Titanate Pyrochlores. J. Solid State. Chem. 177 (6), 1858-1866. doi:10.1016/j.jssc.2004.01.009

Heremans, C., Wuensch, B. J., Stalick, J. K. W., and Prince, E. (1995). Fast-Ion Conducting $\mathrm{Y}_{2}\left(\mathrm{Zr}_{\mathrm{x}} \mathrm{Ti}_{1-\mathrm{x}}\right)_{2} \mathrm{O}_{7}$ Pyrochlores: Neutron Rietveld Analysis of Disorder Induced by Zr Substitution. J. Solid State. Chem. 117 (1), 108-121. doi:10.1006/jssc.1995.1253

Jiang, C, KurtSickafus, E., ChristopherStanek, R., SvenRudin, P., and Uberuaga, B. P. (2012). Cation Disorder in $\mathrm{MgX}_{2} \mathrm{O}_{4}(\mathrm{X}=\mathrm{Al}, \mathrm{Ga}$, in) Spinels from First Principles. Phys. Rev. B 86 (2), 024203. doi:10.1103/physrevb.86.024203

Jiang, C., Stanek, C. R., Sickafus, K. E., and Uberuaga, B. P. (2009). First-Principles Prediction of Disordering Tendencies in Pyrochlore Oxides. Phys. Rev. B 79 (10), 104203. doi:10.1103/physrevb.79.104203

Jiang, C., and Uberuaga, B. P. (2016). Efficient Ab-Initio Modeling of Random Multicomponent Alloys. Phys. Rev. Lett. 116 (10), 105501. doi:10.1103/ physrevlett.116.105501

Kowalski, P. M. (2020). Formation Enthalpy of $\operatorname{Ln}_{2} \mathrm{~B}_{2} \mathrm{O}_{7}$-type (B = Ti, Sn, Hf, Zr) Compounds. Scripta Materialia 189 (December), 7-10. doi:10.1016/ j.scriptamat.2020.07.048
Kreller, C. R., and Uberuaga, B. P. (2021). The Role of Cation Ordering and Disordering on Mass Transport in Complex Oxides. Curr. Opin. Solid State. Mater. Sci. 25 (2), 100899. doi:10.1016/j.cossms.2021.100899

Kumar, M., Raj, I. A., and Pattabiraman, R. (2008). $\mathrm{Y}_{2} \mathrm{Zr}_{2} \mathrm{O}_{7}$ (YZ)-pyrochlore Based Oxide as an Electrolyte Material for Intermediate Temperature Solid Oxide Fuel Cells (ITSOFCs)-Influence of Mn Addition on YZ. Mater. Chem. Phys. 108 (1), 102-108. doi:10.1016/j.matchemphys.2007.09.010

Lang, M., Fuxiang, Z., Jiaming, Z., Jianwei, W., Jie, L., William, J. W., et al. (2010). Review of $\mathrm{A}_{2} \mathrm{~B}_{2} \mathrm{O}_{7}$ Pyrochlore Response to Irradiation and Pressure. Nucl. Instr. Methods Phys. Res. Section B: Beam Interactions Mater. Atoms 268 (19), 2951-2959. doi:10.1016/j.nimb.2010.05.016

Lehmann, H., Pitzer, D., Pracht, G., Vassen, R., and Stöver, D. (2003). Thermal Conductivity and Thermal Expansion Coefficients of the Lanthanum RareEarth-Element Zirconate System. J. Am. Ceram. Soc. 86 (8), 1338-1344. doi:10.1111/j.1151-2916.2003.tb03473.x

Li, Y., and Kowalski, P. M. (2018). Energetics of Defects Formation and Oxygen Migration in Pyrochlore Compounds from First Principles Calculations. J. Nucl. Mater. 505 (July), 255-261. doi:10.1016/j.jnucmat.2017.11.005

Li, Y., Kowalski, P. M., Beridze, G., Birnie, A. R., Finkeldei, S., and Bosbach, D. (2015). "Defect Formation Energies in A2B2O7 Pyrochlores." Scripta Materialia 107 (October), 18-21. doi:10.1016/j.scriptamat.2015.05.010

Li, Y. H., Uberuaga, B. P., Jiang, C., Choudhury, S., Valdez, J. A., Patel, M. K., et al. (2012). Role of Antisite Disorder on Preamorphization Swelling in Titanate Pyrochlores. Phys. Rev. Lett. 108(19): 195504. doi:10.1103/physrevlett.108.195504

Li, F., Zhou, L., Liu, J.-X., Liang, Y., and Zhang, G.-J. (2019). High-Entropy Pyrochlores with Low thermal Conductivity for Thermal Barrier Coating Materials. J. Adv. Ceram. 8 (4), 576-582. doi:10.1007/s40145-019-0342-4

Lian, J., Helean, K. B., Kennedy, B. J., Wang, L. M., Navrotsky, A., and Ewing, R. C. (2006). Effect of Structure and Thermodynamic Stability on the Response of Lanthanide Stannate Pyrochlores to Ion Beam Irradiation. J. Phys. Chem. B 110 (5), 2343-2350. doi:10.1021/jp055266c

Lian, J., Wang, L., Chen, J., Sun, K., Ewing, R. C., Farmer, J. M., et al. (2003). The Order-Disorder Transition in Ion-Irradiated Pyrochlore. Acta Materialia 51 (5), 1493-1502. doi:10.1016/s1359-6454(02)00544-X

Lian, J., Chen, J., Wang, L. M., Ewing, R. C., Farmer, J. M., Boatner, L. A., et al. (2003). Radiation-induced Amorphization of Rare-Earth Titanate Pyrochlores. Phys. Rev. B 68 (13), 134107. doi:10.1103/physrevb.68.134107

Liu, Y., Leslie Withers, R., and Norén, L. (2004). "The Pyrochlore to 'Defect Fluorite' Transition in the $\mathrm{Y}_{2}\left(\mathrm{Zr}_{\mathrm{y}} \mathrm{Ti}_{1-\mathrm{y}}\right)_{2} \mathrm{O}_{7}$ System and its Underlying Crystal Chemistry." J. Solid State. Chem. 177 (12), 4404-4412. doi:10.1016/ j.jssc.2004.09.014

Lumpkin, G. R. (2006). Ceramic Waste Forms for Actinides. Elements 2 (6), 365-372. doi:10.2113/gselements.2.6.365

Lutique, S., Staicu, D., Konings, R. J. M., Rondinella, V. V., Somers, J., and Wiss, T. (2003). Zirconate Pyrochlore as a Transmutation Target: Thermal Behaviour and Radiation Resistance against Fission Fragment Impact. J. Nucl. Mater. 319 (June), 59-64. doi:10.1016/s0022-3115(03)00134-x

Matsumoto, U., Ogawa, T., Kitaoka, S., Moriwake, H., and Tanaka, I. (2020). "First-Principles Study on the Stability of Weberite-type, Pyrochlore, and Defect-Fluorite Structures of $\mathrm{A}_{2}{ }^{3+} \mathrm{B}_{2}{ }^{4+} \mathrm{O}_{7}\left(\mathrm{~A}=\mathrm{Lu}^{3+}-\mathrm{La}^{3+}, \mathrm{B}=\mathrm{Zr}^{4+}, \mathrm{Hf}^{4+}\right.$, $\mathrm{Sn}^{4+}$, and $\mathrm{Ti}^{4+}$ ). J. Phys. Chem. C 124 (37), 20555-20562. doi:10.1021/ acs.jpcc.0c05443

Minervini, L, Grimes, R. W., and Sickafus, K. E. (2004). Disorder in Pyrochlore Oxides. J. Am. Ceram. Soc. 83 (8), 1873-1878. doi:10.1111/j.11512916.2000.tb01484.x

Minervini, L., RobinGrimes, W., Yasunori, T., Withers, R. L., and Sickafus, K. E. (2002). The Oxygen Positional Parameter in Pyrochlores and its Dependence on Disorder. Philosophical Mag. A 82 (1), 123-135. doi:10.1080/ 01418610208240001

Norberg, S. T., Hull, S., Eriksson, S. G., Ahmed, I., Kinyanjui, F., and Biendicho, J. J.. (2012). Pyrochlore to Fluorite Transition: The $\mathrm{Y}_{2}\left(\mathrm{Ti}_{1-\mathrm{x}} \mathrm{Zr}_{\mathrm{x}}\right)_{2} \mathrm{O}_{7}(0.0 \leq \mathrm{X} \leq 1.0)$ System. Chem. Mater. 24 (22), 4294-4300. doi:10.1021/cm301649d

Pan, W., Phillpot, S. R., Wan, C., Chernatynskiy, A., and Qu, Z. (2012). Low thermal Conductivity Oxides. MRS Bull. 37 (10), 917-922. doi:10.1557/ mrs.2012.234

Panero, W. R., Stixrude, L., and Ewing, R. C. (2004). First-Principles Calculation of Defect-Formation Energies in the $\mathrm{Y}_{2}(\mathrm{Ti}, \mathrm{Sn}, \mathrm{Zr})_{2} \mathrm{O}_{7}$ pyrochlore. Physical Review $B$ 70(5): 054110. doi:10.1103/physrevb.70.054110 
Pilania, G., Kocevski, V., Valdez, J. A., Kreller, C. R., and Uberuaga, B. P. (2020). "Prediction of Structure and Cation Ordering in an Ordered Normal-Inverse Double Spinel.” Commun. Mater. 1 (1), 84. doi:10.1038/s43246-020-00082-2

Pilania, G., Puchala, B., and Uberuaga, B. P. (2019). Distortion-Stabilized Ordered Structures in A2BB'O7 Mixed Pyrochlores. Npj Comput. Mater. 5 (1), 7. doi:10.1038/s41524-018-0144-1

Pirzada, M. (2001). Oxygen Migration in $\mathrm{A}_{2} \mathrm{~B}_{2} \mathrm{O}_{7}$ Pyrochlores. Solid State Ionics 140 (3-4), 201-208. doi:10.1016/s0167-2738(00)00836-5

Popov, V. V., Menushenkov, A. P., Gaynanov, B. R., Ivanov, A. A., dAcapito, F., Puri, A., et al. (2018). Formation and Evolution of Crystal and Local Structures in Nanostructured $\mathrm{Ln}_{2} \mathrm{Ti}_{2} \mathrm{O}_{7}(\mathrm{Ln}=\mathrm{Gd}-\mathrm{Dy})$. J. Alloys Compounds 746 (May), 377-390. doi:10.1016/j.jallcom.2018.02.263

Popov, V. V., Menushenkov, A. P., Yaroslavtsev, A. A., Zubavichus, Y. V., Gaynanov, B. R., Yastrebtsev, A. A., et al. (2016). Fluorite-Pyrochlore Phase Transition in Nanostructured $\mathrm{Ln}_{2} \mathrm{Hf}_{2} \mathrm{O}_{7}(\mathrm{Ln}=\mathrm{La}-\mathrm{Lu})$. J. Alloys Compounds 689 (December), 669-679. doi:10.1016/j.jallcom.2016.08.019

Predith, A., Ceder, G., Wolverton, C., Persson, K., and Mueller, T. (2008). Ab Initioprediction of Ordered Ground-State Structures in $\mathrm{ZrO}_{2}-\mathrm{Y}_{2} \mathrm{O}_{3}$. Phys. Rev. B 77 (14), 144104. doi:10.1103/physrevb.77.144104

Raison, P. E., and Haire, R. G. (2001). Zirconia-Based Materials for Transmutation of Americium and Curium: Cubic Stabilized Zirconia and Zirconium Oxide Pyrochlores. Prog. Nucl. Energ. 38 (3-4), 251-254. doi:10.1016/s0149-1970(00)00110-4

Rushton, M. J. D., Grimes, R. W., Stanek, C. R., and Owens, S. (2004). Predicted Pyrochlore to Fluorite Disorder Temperature for A2Zr2O7 Compositions. J. Mater. Res. 19 (6), 1603-1604. doi:10.1557/jmr.2004.0231

Rushton, M. J. D., Stanek, C. R., Cleave, A. R., Uberuaga, B. P., Sickafus, K. E., and Grimes, R. W. (2007). Simulation of Defects and Defect Processes in Fluorite and Fluorite Related Oxides: Implications for Radiation Tolerance. Nucl. Instr. Methods Phys. Res. Section B: Beam Interactions Mater. Atoms 255 (1), 151-157. doi:10.1016/j.nimb.2006.11.018

Saradhi, M. P., Ushakov, S. V., and Navrotsky, A. (2012). Fluorite-Pyrochlore Transformation in $\mathrm{Eu}_{2} \mathrm{Zr}_{2} \mathrm{O}_{7}$ Direct Calorimetric Measurement of Phase Transition, Formation and Surface Enthalpies. RSC Adv. 2 (8), 3328. doi:10.1039/c2ra00727d

Sattonnay, G., Sellami, N., Thomé, L., Legros, C., Grygiel, C., Monnet, I., et al. (2013). Structural Stability of $\mathrm{Nd}_{2} \mathrm{Zr}_{2} \mathrm{O}_{7}$ Pyrochlore Ion-Irradiated in a Broad Energy Range. Acta Materialia 61 (17), 6492-6505. doi:10.1016/ j.actamat.2013.07.027

Schelling, P. K., Phillpot, S. R., and Grimes, R. W. (2004). Optimum Pyrochlore Compositions for Low thermal Conductivity. Philosophical Mag. Lett. 84 (2), 127-137. doi:10.1080/09500830310001646699

Shamblin, J., Mikhail, F., Joerg, N., CameronTracy, L., Fuxiang, Z., Sarah, F., et al. (2016). Probing Disorder in Isometric Pyrochlore and Related Complex Oxides. Nat. Mater. 15 (5), 507-511. doi:10.1038/nmat4581

Shlyakhtina, A. V., and Shcherbakova, L. G. (2012). New Solid Electrolytes of the Pyrochlore Family. Russ. J. Electrochem. 48 (1), 1-25. doi:10.1134/ s1023193512010144

Sickafus, K. E., Grimes, R. W., Valdez, J. A., Cleave, A., Tang, M., Ishimaru, M., et al. (2007). Radiation-induced Amorphization Resistance and Radiation Tolerance in Structurally Related Oxides. Nat. Mater 6(3): 217-223. doi:10.1038/nmat1842

Sickafus, K. E. (2000). Radiation Tolerance of Complex Oxides. Science 289 (5480), 748-751. doi:10.1126/science.289.5480.748

Solomon, J. M., Shamblin, J., Lang, M., Navrotsky, A., and Asta, M. (2016). Chemical Ordering in Substituted Fluorite Oxides: A Computational Investigation of $\mathrm{Ho}_{2} \mathrm{Zr}_{2} \mathrm{O}_{7}$ and $\mathrm{RE}_{2} \mathrm{Th}_{2} \mathrm{O}_{7}$ ( $\left.\mathrm{RE}=\mathrm{Ho}, \mathrm{Y}, \mathrm{Gd}, \mathrm{Nd}, \mathrm{La}\right)$. Scientific Rep. 6 (1), 38772. doi:10.1038/srep38772

Stanek, C. R., and Grimes, R. W. (2002). Prediction of Rare-Earth A2Hf2O7 Pyrochlore Phases. J. Am. Ceram. Soc. 85 (8), 2139-2141. doi:10.1111/j.11512916.2002.tb00423.x

Stanek, C. R., Jiang, C., Uberuaga, B. P., Sickafus, K. E., Cleave, A. R., and Grimes, R. W. (2009). Predicted Structure and Stability of $\mathrm{A}_{4} \mathrm{~B}_{3} \mathrm{O}_{12} \delta$-Phase Compositions. Phys. Rev. B 80 (17), 174101. doi:10.1103/ physrevb.80.174101

Subramanian, M. A., Aravamudan, G., and Subba Rao, G. V. (1983). Oxide Pyrochlores a Review. Prog. Solid State. Chem. 15 (2), 55-143. doi:10.1016/ 0079-6786(83)90001-8
Tanaka, M., Kitaoka, S., Yoshida, M., Sakurada, O., Hasegawa, M., Nishioka, K., et al. (2017). Structural Stabilization of EBC with thermal Energy Reflection at High Temperatures. J. Eur. Ceram. Soc. 37 (13), 4155-4161. doi:10.1016/ j.jeurceramsoc.2017.04.055

Todorov, I. T., Purton, J. A., Allan, N. L., and Dove, M. T. (2006). Simulation of Radiation Damage in Gadolinium Pyrochlores. J. Phys. Condensed Matter 18 (7), 2217-2234. doi:10.1088/0953-8984/18/7/010

Tryon, B., Feng, Q., Pollock, T. M., Wellman, R. G., Nicholls, J. R., Murphy, K. S., et al. (2006). Multilayered Ruthenium-Modified Bond coats for thermal Barrier Coatings. Metall. Mat. Trans. A. 37 (11), 3347-3358. doi:10.1007/ bf02586169

Uberuaga, B. P., Ming, T., Chao, J., Valdez, J. A., Smith, R., et al. (2015). Opposite Correlations between Cation Disordering and Amorphization Resistance in Spinels versus Pyrochlores. Nature Communications 6 (1). doi:10.1038/ ncomms 9750

Uberuaga, B. P., Jiang, C., Stanek, C. R., Sickafus, K. E., Scott, C., and Smith, R. (2014). Prediction of Irradiation Spectrum Effects in Pyrochlores. JOM 66 (12), 2578-2582. doi:10.1007/s11837-014-1158-x

Ushakov, S. V., Navrotsky, A., Tangeman, J. A., and Helean, K. B. (2007). Energetics of Defect Fluorite and Pyrochlore Phases in Lanthanum and Gadolinium Hafnates. J. Am. Ceram. Soc. 90 (4), 1171-1176. doi:10.1111/ j.1551-2916.2007.01592.x

Vaßen, R., Jarligo, M. O., Steinke, T., Mack, D. E., and Stöver, D. (2010). Overview on Advanced thermal Barrier Coatings. Surf. Coat. Technology 205 (4), 938-942. doi:10.1016/j.surfcoat.2010.08.151

Wang, S. X., Wang, L. M., Ewing, R. C., and Govindan Kutty, K. V. (2000). Ion Irradiation of Rare-Earth- and Yttrium-Titanate-Pyrochlores. Nucl. Instr. Methods Phys. Res. Section B: Beam Interactions Mater. Atoms 169 (1-4), 135-140. doi:10.1016/s0168-583x(00)00030-6

Wang, X. J., Xiao, H. Y., Zu, X. T., Zhang, Y., and Weber, W. J. (2013). Ab Initio Molecular Dynamics Simulations of Ionsolid Interactions in $\mathrm{Gd}_{2} \mathrm{Zr}_{2} \mathrm{O}_{7}$ and $\mathrm{Gd}_{2} \mathrm{Ti}_{2} \mathrm{O}_{7}$. J. Mater. Chem. C 1 (8), 1665. doi:10.1039/c2tc00192f

Wiebe, C. R., and Hallas, A. M. (2015). Frustration under Pressure: Exotic Magnetism in New Pyrochlore Oxides. APL Mater. 3 (4), 041519. doi: $10.1063 / 1.4916020$

Wilde, P. (1998). Defects and Diffusion in Pyrochlore Structured Oxides. Solid State Ionics 112 (3-4), 173-183. doi:10.1016/s0167-2738(98)00190-8

Winter, M. R., and Clarke, D. R. (2007). Oxide Materials with Low Thermal Conductivity. J. Am. Ceram. Soc. 90 (2), 533-540. doi:10.1111/j.15512916.2006.01410.x

Wright, A. J., Wang, Q., Hu, C., Yeh, Y.-T., Chen, R., and Luo, J. (2021). Singlephase Duodenary High-Entropy Fluorite/pyrochlore Oxides with an OrderDisorder Transition. Acta Materialia 211, 116858. doi:10.1016/ j.actamat.2021.116858

Wu, J., Wei, X., Padture, N. P., Klemens, P. G., Gell, M., García, E., et al. (2004). Low-Thermal-Conductivity Rare-Earth Zirconates for Potential ThermalBarrier-Coating Applications. J. Am. Ceram. Soc. 85 (12), 3031-3035. doi:10.1111/j.1151-2916.2002.tb00574.x

Wuensch, B. (2000). Connection between Oxygen-Ion Conductivity of Pyrochlore Fuel-Cell Materials and Structural Change with Composition and Temperature. Solid State Ionics 129 (1-4), 111-133. doi:10.1016/s01672738(99)00320-3

Wolff-Goodrich, S., Benjamin, E. H., Jonathan, M. S., and Asta, M.. (2015). Special Quasirandom Structure Modeling of Fluorite-Structured Oxide Solid Solutions with Aliovalent Cation Substitutions. Modelling and Simulation in Materials Science and Engineering 23(5): 055001. doi:10.1088/0965-0393/23/5/055001

Xiao, H. Y., Gao, F., and J Weber, W. (2010). Threshold Displacement Energies and Defect Formation Energies in $\mathrm{Y}_{2} \mathrm{Ti}_{2} \mathrm{O}_{7}$. J. Phys. Condensed Matter 22 (41), 415801. doi:10.1088/0953-8984/22/41/415801

Xiao, H. Y., Weber, W. J., Zhang, Y., and Zu, X. T. (2015). Ab Initio Molecular Dynamics Simulations of Ionsolid Interactions in Zirconate Pyrochlores. Acta Materialia 87 (April), 273-282. doi:10.1016/ j.actamat.2015.01.019

Yamamura, H. (2003). Electrical Conductivity Anomaly Around Fluoritepyrochlore Phase Boundary. Solid State Ionics 158 (3-4), 359-365. doi:10.1016/s0167-2738(02)00874-3 
Yang, L., Wang, P., Zhang, C., Liu, Y., Cui, Y., Zhang, L., et al. (2019). Composition-Dependent Intrinsic Defect Structures in Pyroclore $\mathrm{RE}_{2} \mathrm{~B}_{2} \mathrm{O}_{7}(\mathrm{RE}=\mathrm{La}, \mathrm{Nd}, \mathrm{Gd} ; \mathrm{B}=\mathrm{Sn}, \mathrm{Hf}, \mathrm{Zr})$. J. Am. Ceram. Soc. 103 (1), 645-655. doi:10.1111/jace.16705

Wolff-Goodrich, S., Hanken, B. E., Solomon, J. M., and Asta, M. (2015). Special Quasirandom Structure Modeling of Fluorite-Structured Oxide Solid Solutions With Aliovalent Cation Substitution Model. Simulat. Mater. Sci. Engin. 23 (5), 055001. doi:10.1088/0965-0393/23/5/055001

Zhang, Z., Simon, C. M., Massey de los, R., Gregory, R. L., Brendan, J. K., Peter, E. R. B., et al. (2013). Gradual Structural Evolution from Pyrochlore to Defect-Fluorite in $\mathrm{Y}_{2} \mathrm{Sn}_{2 \mathrm{x}} \mathrm{Zr}_{\mathrm{x}} \mathrm{O}_{7}$ : Average vs Local Structure. J. Phys. Chem. C 117 (50), 26740-26749. doi:10.1021/ jp408682r

Zhang, Z. L., Xiao, H. Y., Zu, X. T., Gao, F., and Weber, W. J. (2009). "FirstPrinciples Calculation of Structural and Energetic Properties for $\mathrm{A}_{2} \mathrm{Ti}_{2} \mathrm{O}_{7}$ $(\mathrm{A}=\mathrm{Lu}, \mathrm{Er}, \mathrm{Y}, \mathrm{Gd}, \mathrm{Sm}, \mathrm{Nd}, \mathrm{La})$. J. Mater. Res. 24 (4), 1335-1341. doi:10.1557/jmr.2009.0152

Zhao, Z., Xiang, H., Dai, F.-Z., Peng, Z., and Zhou, Y. (2019). $\left(\mathrm{La}_{0.2} \mathrm{Ce}_{0.2} \mathrm{Nd}_{0.2} \mathrm{Sm}_{0.2} \mathrm{Eu}_{0.2}\right)_{2} \mathrm{Zr}_{2} \mathrm{O}_{7}$ : A Novel High-Entropy Ceramic with Low thermal Conductivity and Sluggish Grain Growth Rate. J. Mater. Sci. Technology 35 (11), 2647-2651. doi:10.1016/j.jmst.2019.05.054
Zunger, A., Wei, S.-H., Ferreira, L. G., and Bernard, J. E. (1990). Special Quasirandom Structures. Phys. Rev. Lett. 65 (3), 353-356. doi:10.1103/ physrevlett.65.353

Conflict of Interest: The authors declare that the research was conducted in the absence of any commercial or financial relationships that could be construed as a potential conflict of interest.

Publisher's Note: All claims expressed in this article are solely those of the authors and do not necessarily represent those of their affiliated organizations, or those of the publisher, the editors and the reviewers. Any product that may be evaluated in this article, or claim that may be made by its manufacturer, is not guaranteed or endorsed by the publisher.

Copyright (c) 2021 Kocevski, Pilania and Uberuaga. This is an open-access article distributed under the terms of the Creative Commons Attribution License (CC BY). The use, distribution or reproduction in other forums is permitted, provided the original author(s) and the copyright owner(s) are credited and that the original publication in this journal is cited, in accordance with accepted academic practice. No use, distribution or reproduction is permitted which does not comply with these terms. 